\title{
Investigation into Failure in Mining Wire Ropes-Effect of Crystallinity
}

\author{
Sheila Devasahayam ${ }^{1,2}$, Veena Sahajwalla ${ }^{1}$, Michael $\mathrm{Sng}^{3}$ \\ ${ }^{1}$ School of Materials Science \& Engineering, University of New South Wales, Sydney, Australia \\ ${ }^{2}$ School of Science, Information Technology and Engineering, University of Ballarat, Ballarat, Australia \\ ${ }^{3}$ Moly-Cop Ropes Mayfield NSW 2304 PO Box 245C, Newcastle, Australia \\ Email: s.devasahayam@ballarat.edu.au
}

Received January 11, 2013; revised February 13, 2013; accepted February 23, 2013

Copyright (C) 2013 Sheila Devasahayam et al. This is an open access article distributed under the Creative Commons Attribution License, which permits unrestricted use, distribution, and reproduction in any medium, provided the original work is properly cited.

\begin{abstract}
A range of blends of polypropylene-polyethylene are investigated for their mechanical performances. These speciality polymer blends are chemically designed to suit high modulus/high load bearing mining wire rope applications subjected to continued bending and tensile stresses and fluctuating loads and are exposed to extreme weather conditions. In this paper we study the influence of different parameters on the performance of the wire ropes: chemistry of polymer, crystallinity of the polymer matrix, and the morphology. The FTIR and SEM studies revealed that the high fraction of polypropylene in polypropylene-polyethylene matrix lead to early failure as a result of incompatibility and phase segregation and high spherulite sizes of the polymer matrix.
\end{abstract}

Keywords: Mining Wire Ropes; Crystallinity; Polyolefin Blends; Morphology; FTIR; SEM

\section{Introduction}

Mining wire ropes are used for high modulus/high load bearing applications and are exposed to extreme weather conditions. The mining wire ropes are subjected to continued bending and tensile stresses and fluctuating loads, e.g., in drag rope, and shovel hoist rope applications. Historically wire ropes were made of only steel chains with a record of mechanical failure. The flaws in chain links or solid steel bars lead to catastrophic failure. Friction between the individual wires and strands, as a consequence of their twist, cause strand wear and heat resulting in accelerated rust and potential premature rope failure. Mining wire rope consists of several strands of steel wire laid (or "twisted") into a helix featuring a 6 or 8 steel strand construction. The steel is normally made of non-alloy carbon steel with carbon content between $0.4 \%$ and $0.95 \%$. The size and number of wires in each strand, as well as the size and number of strands in the rope greatly affect the characteristics of the rope. In general, a large number of small size wires and strands produce a flexible rope with good resistance to bending fatigue. The rope construction is important for tensile loading (static, live or shock), abrasive wear, crushing, corrosion and rotation. Plastic infusion helps achieve reduced rope fatigue from bending stresses by reducing the internal contact stresses between the strands and the core and provides improved fatigue and abrasion resistance and increased corrosion protection. A plastic-infused core provides a cushion for the outer strand and virtually eliminates interlayer contact wear. The plastic-infused core adds to the core support for the outer strands, further reducing internal stresses and promoting longer service life and under extreme conditions. Plastic-Infusion involves injecting specially engineered polymers under high temperature and pressure into the wire rope. Both the polymer and the wire rope are heated when the polymer is infused as the wire rope is drawn through specially designed dies. Passing the rope through a series of cooling troughs then solidifies the plastic. This plastic will not melt or soften from the heat of normal operating temperatures when in service and is also virtually unaffected by sunlight or cold weather during their life time (6 to 12 weeks). A set of plasticised ropes is expected to typically last between $6-12$ weeks. Benchmark for these wire rope is identified visually as-all plastic still intact at the end of the ropes life, which only wears away due to mechanical abrasion to expose the crown of the strand (the highest point of the strand on a rope which has the thinnest plastic cover) on certain sections of the rope instead of peeling off entirely. Plastic delamination causes a hassle as it trips the machine off when the plastic pieces ac- 
tivate the slack rope indicator in the machine. A typical rope section is shown in Figure 1. There has been recent commercial interest in blends based on isotactic PP and polyolefins (PP-polyolefins) blends, which exhibit improved mechanical strength, tensile strength, enivironmental stress cracking, and low temperature impact properties. Homopolymer of polypropylene (PP) are used for high modulus and long exposure applications, hence find applications in mining wire ropes.

Other plastics of interest in wire ropes include, HMPE (High Modulus Polyethylene), Nylon ${ }^{\circledR}$, Perlon ${ }^{\circledR}$ (Polyamide), Dacron $\AA$, Terylene $\AA$ (Polyester), Polyolefins: Polypropylene and Polyethylene; Kevlar $\AA$, Twaron $\AA$, and Technora ${ }^{\circledR}$ (Aramid): Vectran ${ }^{\circledR}$ (LCAP_-(Liquid Crystal Aromatic Polyester)): Zylon ${ }^{\circledR}$ (PBO-Poly-pphenylenebenzobisoxazole), Poly Vinyl Chloride, Low Density Poly Ethylene, High Density Poly Ethylene, P, nylon 6 (PA6), nylon 11 (PA11), polyvinylidenedifluoride and more [1]. Properties of these wire rope materials based on manufacturer's specifications have been summarised by Barry Cordage [2].

Homopolymer of polypropylene (PP) are homogeneous with single phase, exhibiting large spherulite dimension which affect their mechanical properties adversely. However, the polymer blends/copolymers e.g., polypropylene-polyethylene (PP-PE) are immiscible in each other, and show decline in their mechanical properties due to their incompatibility. They show remarkable phase separation during crystallization. Phase segregation hastens yielding and fracture at interphase boundaries. The micro structure of the polymer matrix greatly influences the mechanical behaviour of the polymer products. Higher crystallinity leads to brittle fracture in polymers as opposed to the amorphous nature of the polymer. The factors affecting the crystallinity include the polymer processing, e.g., during polymer extrusion the slow cooling or the rapid cooling greatly affects the crystallinity in polymers [3]. In this study we focus on if the crystallinity behaviour of the polypropylene-polyethylene blend affects the performance of the mining wire ropes.

\section{Objectives}

The present study involves the characterisation of a set of plastic component of the mining wire ropes to correlate

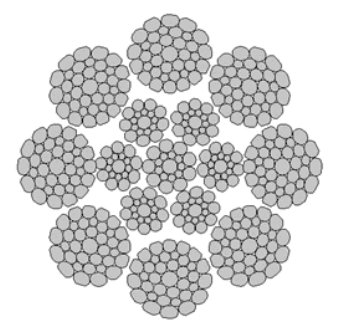

Figure 1. Design of the rope. their performance characteristics. Following properties are investigated in this study:

- Chemistry of the bulk plastic used in wire rope

- Crystallinity

- Morphology

\section{Experimental}

\subsection{Samples}

The Moly-Cop Ropes supplied the mining wire rope samples and the information on their mechanical performance as listed below: wire rope $\mathrm{A}>$ wire rope $\mathrm{B}>$ wire rope $\mathrm{C}$ - wire rope $\mathrm{D}>$ wire rope $\mathrm{E}$. The manufacturers of these wire ropes have not released chemical compositions, structures of these wire ropes.

\subsection{ATR-FTIR Measurements}

The chemical composition and the crystallinity of the plastic component of the mining wire ropes were studied using Perkin Elmer Spotlight 400 FTIR Microscope, a Fourier Transform Infrared (FTIR) spectrometer fitted with Harrick Grazing Angle ATR accessories. This technique probes the surface of a sample (up to 2 microns deep) with infrared energy of varying wavelengths. The detection limit of IR has been noted to be between $2 \%$ and $3 \%$ by weight of the total analysed sample. The technique allows transmittance or absorbance to be measured. The spectra were accumulated for 4 scans at a resolution of $4 \mathrm{~cm}^{-1}$ over the spectral range $500-4000 \mathrm{~cm}^{-1}$ at ambient temperature.

\subsection{Scanning Electron Microscope (SEM) Tests}

The morphology and X-ray microanalysis of the samples were studied using Hitachi S3400 SEM. These instruments are fitted with secondary and backscatter electron detectors that allow for topographic and compositional (atomic number contrast) surface imaging of samples. Samples were carbon coated to render them more conductive.

\section{Results and Discussions}

\subsection{Chemistry of the Bulk Plastic Used in Wire Rope}

Figure 2 shows the ATR-FTIR spectra of all the samples between $4000-650 \mathrm{~cm}^{-1}$. Figures 3-5 highlight different spectral regions of significance. The samples were identified to be comprised of copolymer of polyethylene (PE) and isotactic polypropylene (PP) based on the characteristic peaks of PP and PE presented in Tables $\mathbf{1}$ and $\mathbf{2}$.

The $\mathrm{CH}_{3}$ bands at $2958 \mathrm{~cm}^{-1}, 2885 \mathrm{~cm}^{-1}$ and 1380 $\mathrm{cm}^{-1}$, the $\mathrm{CH}_{2}$ bands at $2838 \mathrm{~cm}^{-1}$ and $1461 \mathrm{~cm}^{-1}$, and the 


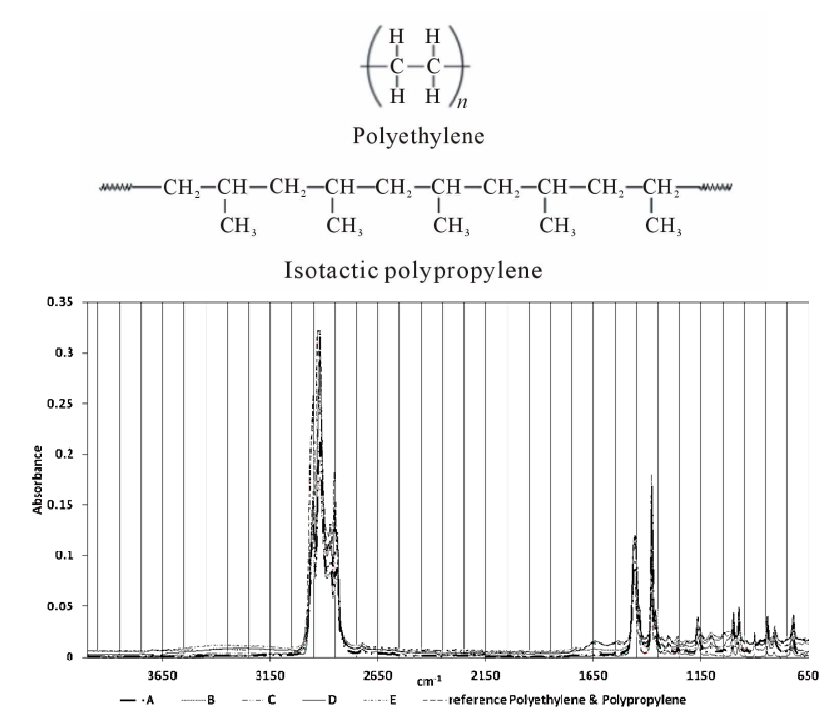

Figure 2. FTIR spectra of all the samples studied.

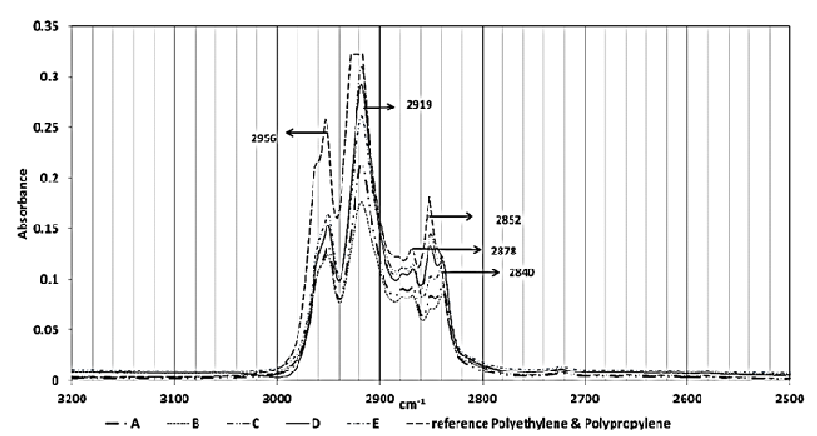

Figure 3. FTIR spectral region between 3200 and $2500 \mathrm{~cm}^{-1}$ of all the samples studied

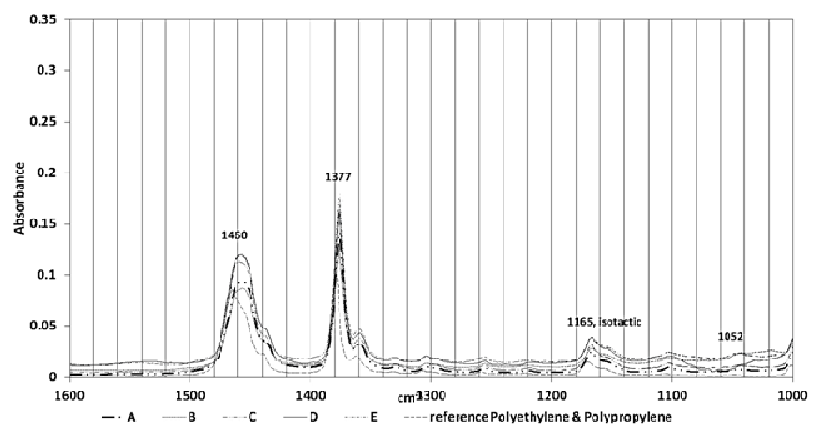

Figure 4. FTIR Spectral region between 1600 and $1000 \mathrm{~cm}^{-1}$ of all samples

three isotactic bands at $1165 \mathrm{~cm}^{-1}, 997 \mathrm{~cm}^{-1}$ and 977 $\mathrm{cm}^{-1}$ confirmed the presence of the isotactic polypropylene component in all the wire ropes studies. The presence of following $\mathrm{CH}_{2}$ bands at $2917 \mathrm{~cm}^{-1}, 2860 \mathrm{~cm}^{-1}$, $1464 \mathrm{~cm}^{-1}$ and $718 \mathrm{~cm}^{-1}$, and the $\mathrm{CH}_{3}$ band at $731 \mathrm{~cm}^{-1}$, and $1379 \mathrm{~cm}^{-1}$ confirmed the presence of polyethylene component of these wire ropes. A reference spectra of PE-PP from FTIR library is included in the figures to corroborate the presence of PP-PE in the wire samples.

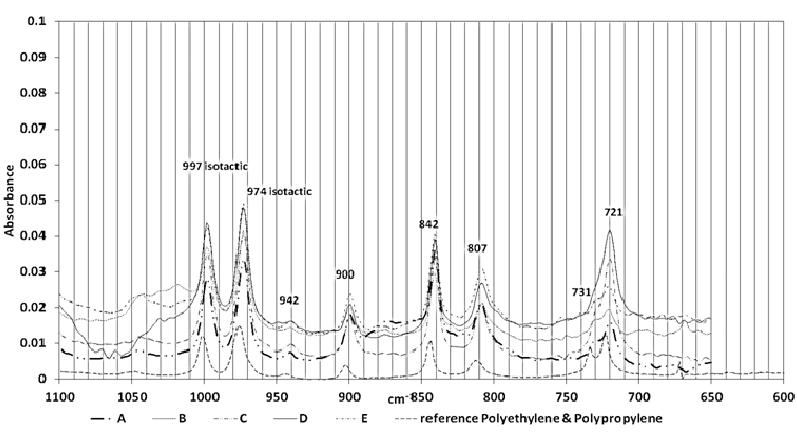

Figure 5. FTIR Spectral region between 1100 and $600 \mathrm{~cm}^{-1}$ of all samples

Table 1. Assignment of IR absorption peaks for PP1,15.

\begin{tabular}{cc}
\hline Wavenumber $\left(\mathbf{c m}^{-\mathbf{1}}\right)$ & Interpretation \\
\hline 2958 & $v$ (stretching) $\mathrm{CH}_{3}$ \\
2885 & $v \mathrm{CH}_{3}$ \\
2838 & $v$ as $\mathrm{CH}_{2}$ \\
1461 & $\delta$ (symmetrical bending vibration) $\mathrm{CH}_{2}$ \\
1380 & $\delta \mathrm{CH}_{3}$ \\
1165 & Isotactic band \\
997 & Isotactic band \\
977 & Isotactic band \\
\hline
\end{tabular}

Table 2. Assignment of IR Absorption Peaks for PE16.

\begin{tabular}{cc}
\hline Wavenumber $\left(\mathbf{c m}^{-1}\right)$ & Interpretation \\
\hline 3477 & Moisture \\
2917 & $v$ (stretching) $\mathrm{CH}_{2}$ \\
2860 & $v \mathrm{CH}_{2}$ \\
1464 & Methylene deformation \\
1379 & $\delta \mathrm{C}-\mathrm{CH} 3$ bending \\
1162 & $v \mathrm{C}-\mathrm{C}$ \\
1059 & $\delta \mathrm{C}-\mathrm{CH}$ \\
731 & $\gamma$ (rocking) $\mathrm{CH}_{3}$ \\
718 & $\mathrm{CH}_{2}$ deformation \\
\hline
\end{tabular}

\subsection{Crystallinity}

\subsubsection{Crystallinity of Polypropylene}

Crystallinity, $X c$, for isotactic polypropylene can be evaluated considering a crystalline peak at $841 \mathrm{~cm}^{-1}$ and a peak insensitive to phase content, at $973 \mathrm{~cm}^{-1}$ using Lambert and Beer's law [4,5] (Figure 6).

The relative areas of the absorption bands for the groups of interest in the spectra can be quantified using Equation (1).

$$
X c=\frac{a_{a v}}{a_{c r}} \times \frac{A_{c r}}{A_{a v}}
$$

$A_{c r}=$ absorbancies of crystalline fraction 
$A_{a v}=$ absorbancies of peak insensitive to phase content $a_{a v}=$ absorptivities of peak insensitive to phase content $a_{c r}=$ absorptivities of crystalline fraction.

For isotactytic polypropylene $a v=973 \mathrm{~cm}^{-1}, c r=841$ $\mathrm{cm}^{-1}$ and a973/a841 $=0.57$. The crystallinity determined using Equation (1) is presented in Figure 7.

The crystallinity, $X c$, for isotactic polypropylene of the wire ropes showed following trend: $\mathrm{B}<\mathrm{E}<\mathrm{C}<\mathrm{A}<\mathrm{D}$. The evolution of crystallinity and the associated mechanical properties during polymer processing in the extruded polymer samples are attributed to different cooling rates. The crystallinity increases when the polymer sample is slow cooled [3]. It is believed that in slow cooling, the polymer chains are exposed near the maximum crystallization temperature for a longer period, and therefore, the crystallization is activated. In fast cooling, the polymer melt go through the maximum crystallization temperature very quickly, leaving most of the molecular chains in amorphous form. What this means is higher crystallinity results in a harder and more thermally stable, but also more brittle material, whereas the amorphous regions provide certain elasticity and impact resistance. Samples cooled slowly from the melt state, form larger and denser microstructures. Based on the mechanical performance trend of the samples, where sample A performed better than sample B showing following trend, $\mathrm{A}>\mathrm{B}>\mathrm{C}-\mathrm{D}>\mathrm{E}$, the trend observed in the crystallinity, $X c$ of the samples could not be correlated with the performance trend.

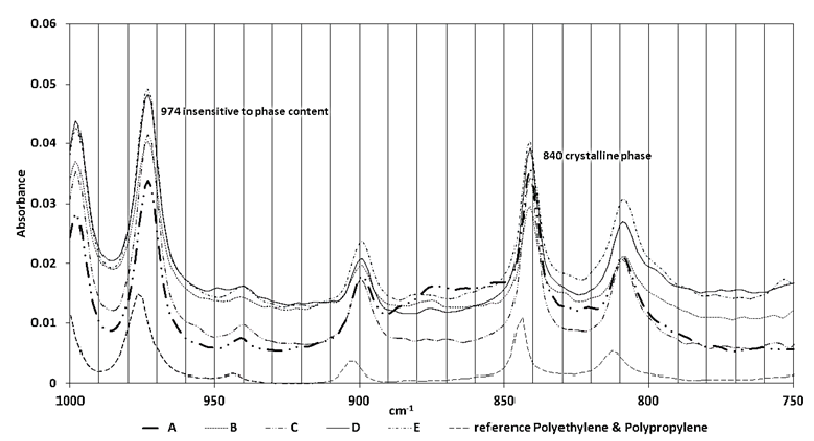

Figure 6. Crystalline and amorphous region in Polypropylene for different samples.

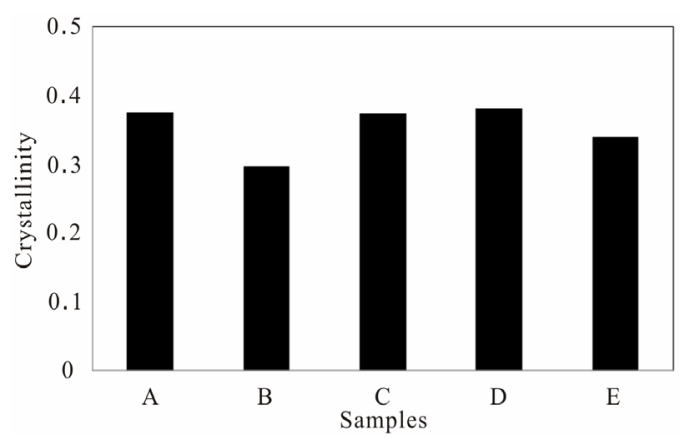

Figure 7. Crystallinity in various wire ropes tested.

\subsubsection{Crystallinity of Polyethylene}

Crystallinity of Polyethylene is estimated from the ratio of $731 \mathrm{~cm}^{-1}$ to $719 \mathrm{~cm}^{-1}$ absorbancies (ASTM D5576). Figure 8 represents the crystalline and amorphous region of PE. The crystallinity in PE is given by A731/A719. Figure 8 shows samples A, D and C to contain hi- gher amorphous content than the crystalline phase. Samples E and $\mathrm{B}$ also show higher amorphous content than the crystalline content but only slightly higher. Again the performance trend of the wire ropes and the trend observed in the PE crystallinity could not be correlated.

\subsubsection{Percent Polypropylene in the Sample}

Though the samples were identified to be copolymer of $\mathrm{PP}$ and $\mathrm{PE}$, the ratio of the $\mathrm{PP}$ and $\mathrm{PE}$ in the wire rope samples have not been released. In order to investigate if the PP:PE could have bearing on the mechanical performance of the wire ropes, the proportion of polypropylene (PP) in the copolymer (Figures 9 and 10) was determined using the ATR-FTIR technique. The relative ratio of the absorbance (integrated area) of two peaks in the rocking wagging region, a peak at $1168 \mathrm{~cm}^{-1}$ characteristic for methyl group wagging in PP and a peak at 720 $\mathrm{cm}^{-1}$ arising from ethylene rocking and typical for HDPE were chosen [6,7].

The PP content is estimated using the expression A1168/(A1168 + A720).

The results show that the sample E exhibited the high-

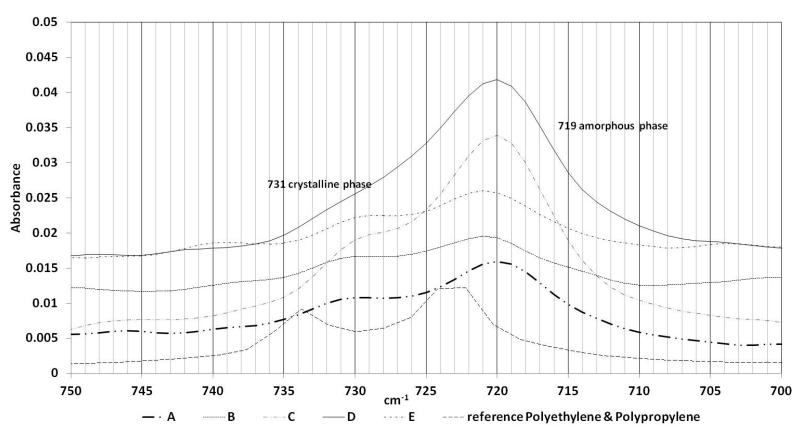

Figure 8. Figure crystalline and amorphous region in polyethylene.

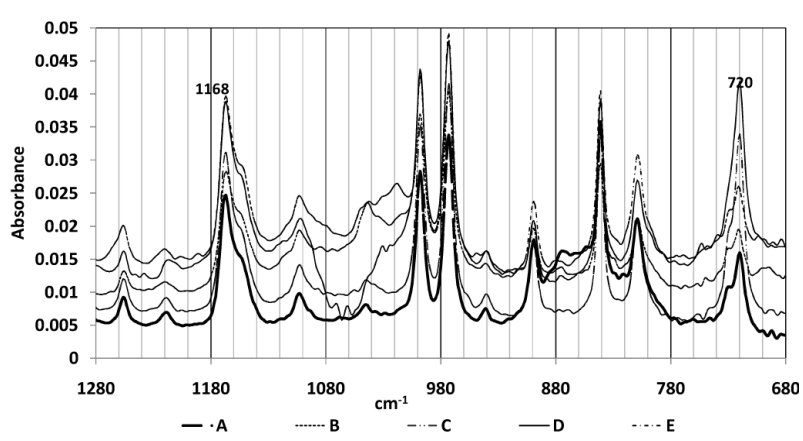

Figure 9. Polypropylene and polyethylene regions. 


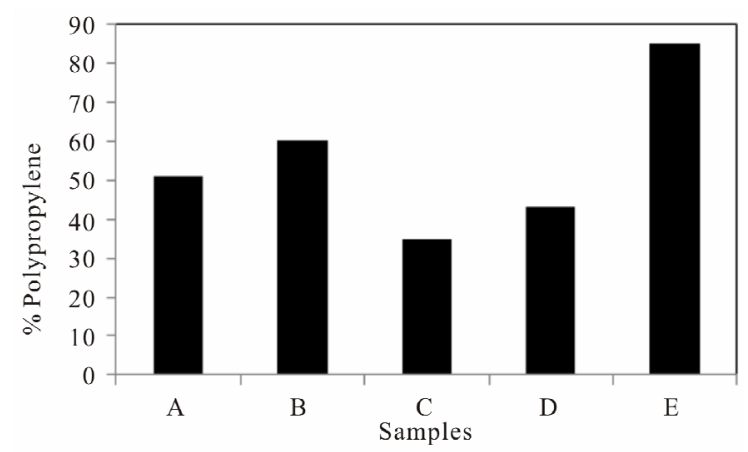

Figure 10. \% polypropylene in samples.

est PP content compared to the other samples, followed by sample $\mathrm{B}$ and $\mathrm{A}$ leading to the proposition that the amount of PP could perhaps affect the performance of these wire ropes, that is high PP content as found in sample E could lead to the early failure in these samples.

Crystallinity in PP was plotted against \% PP to determine the effect of PP content of the matrix on the crystallinity (Figure 11). A general decreasing trend in crystallinity was observed as the \% PP increased.

\subsubsection{Scanning Electron Microscope (SEM) Test}

SEM images of sample E shown in Figures 12(a) and (b) appear to be flaky, non-compatibilized exhibiting broken texture with large crystallites.

On the contrary, the SEM images of sample A and B, Figures 13 and 14 appear to be orderly, uniformly distributed with smaller spherulite structures. Sample A exhibited smaller spherulite structures than sample B and E.

\subsection{Effect of \% PP in Matrix}

The results indicate that perhaps the PP content of the matrix could be responsible for the observed differences in the behaviour in different mining wire ropes. In the present study it is observed from the SEM images (Figures 12-14) that as the \% PP increased, the spherulite size increased, the crystallinity (Figure 11) decreased and the overall performance of the mining rope deteriorated.

High modulus applications of homopolymer of polypropylene exhibiting homogeneous single phase, is limited by their large spherulite dimension affecting their mechanical properties adversely. This has led to a great deal of commercial interest In recent years in blends based on isotactic polypropylene and other polyolefins in nature due to improved mechanical strength, tensile strength, enivironmental stress cracking, low temperature impact properties exhibited by these blends.

The PP and PE blends are generally known to be incompatible $[8,9]$ due to their crystallinities preventing their complete homogeneous blending. Decrease in me

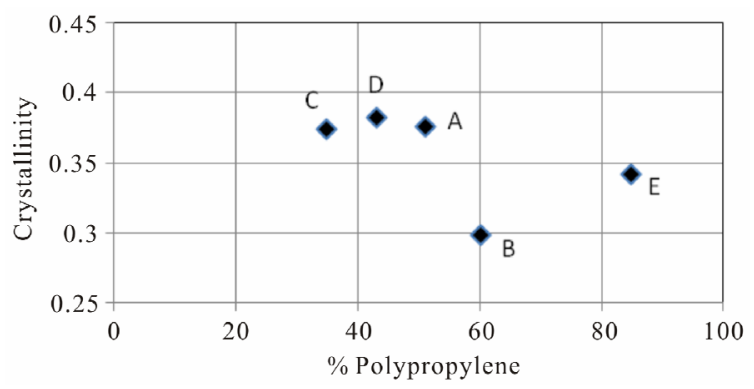

Figure 11. Crystallinity vs. \% polypropylene.

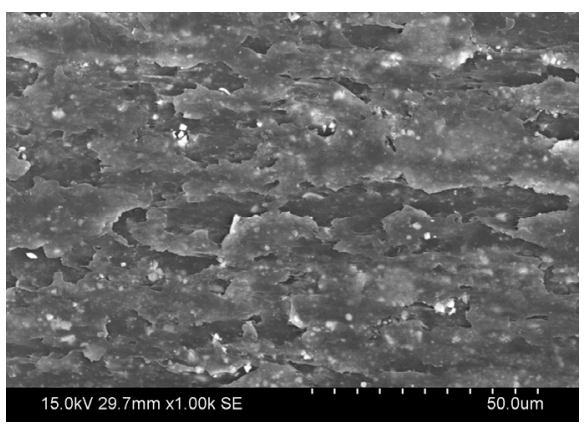

(a)

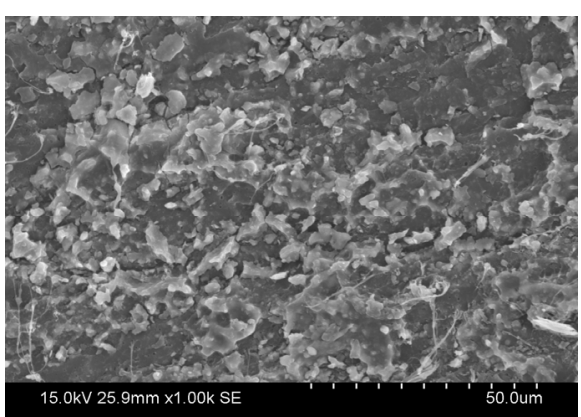

(b)

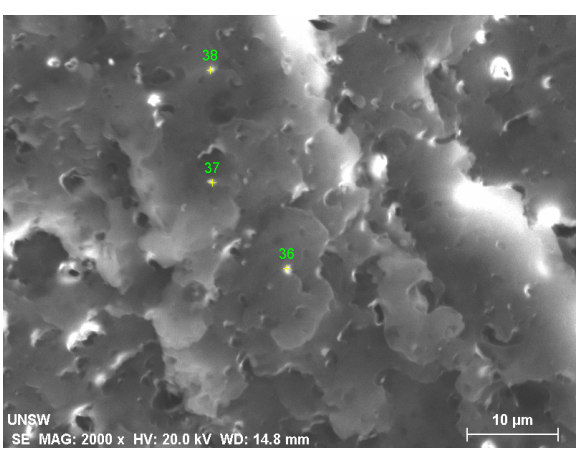

(c)

Figures 12. Morphology of sample E showing non-compatibilized sample rupture, wide voids and gaps.

chanical properties, including impact strength, strain at break and ductile to brittle transition, especially related to morphology are attributed to the strong phase separation leading to a coarse phase structure and low interfacial adhesion between the two phases. Previous studies on mechanical properties of the PE-PP blends reveal direct 


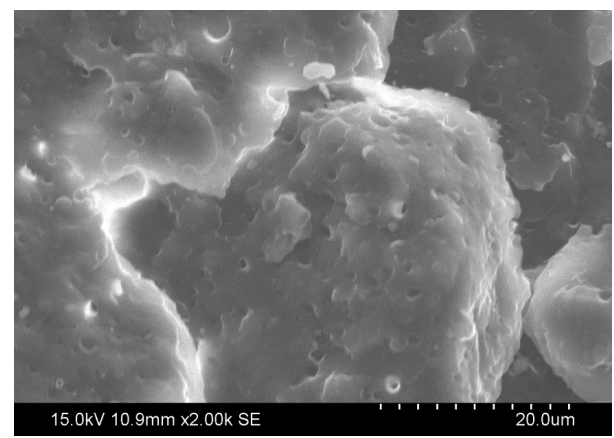

Figure 13. SEM image of surface of sample $B$.

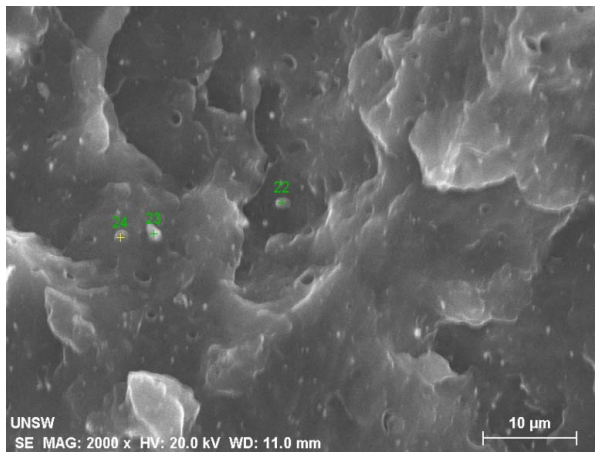

Figure 14. SEM image of surface of sample $A$.

correlation between the morphology and the tensile properties, the spherulite size and the crystallinity being controlled by the PE-PP ratio. The impact strength and adhesion are improved when the particles are smaller with narrower particles size distributions, and when there is stronger adhesion between particle and the matrix [1017]. Lovinger and Williams [18] correlated the morphological effects, such as spherulite sizes, inter crystalline links between lamellae, and the detailed structure of the two incompatible phases and of their mutual boundaries, with the tensile behaviour of PE/PP blends. They reported deterioration of mechanical properties as a result of incompatibility and phase segregation which hastens yielding and fracture at interphase boundaries. Studies have shown that yield stress and ultimate strength are improved with decreasing spherulite size, primarily because yielding and failure are commonly initiated at inter spherulitic boundaries. The PE in the blends reduce the average spherulite size, increase the overall crystallinity, promoting formation of intercrystalline links, and increases modulus and strength [13,19-21].

Padden and Keithz [22,23] have shown that in contrast to $P E$ in which there is a very high density of inter crystalline links, PP has only a few such links, primarily because of the slow growth of its spherulites. In this manner, and because of its higher crystallinity and its role in reducing spherulite sizes, $\mathrm{PE}$ functions as a stiffener for the PP matrix. It is reported that a higher PP content in a blend leads to a higher void fraction compared to sam- ples with a lower PP content [24,25].

In present study the higher PP content in the sample E, with lower crystallinity but larger spherulite size is determined to be contributing to the observed early failure, as well as the higher void fraction compared to samples with lower polypropylene content (e.g., samples A and B).

\section{Conclusion}

The study pertaining to failure in mining wire ropes revealed all the samples were made of copolymer of polyethylene and Polypropylene, with different PP:PE content. Sample E exhibited higher polypropylene content, lower crystallinity and bigger spehrulite size compared to the other samples. The SEM results showed highly ruptured and segregated morphology for sample E. SEM images of samples A and B with lower \% PP are ordered/ homogenised and well plasticised with uniformly distributed microcellular structures. Even though the crystallinity (crystalline content) results from FTIR study of all the samples appear to be comparable and not correlated to their performance characteristics, the spherulite size of samples could be directly correlated to their performance behaviour. The \% PP had direct influence on the spherulite size with higher \% PP showing larger spherulite structure and lower crystallinity while the higher PE content increased the crystallinity of the samples. It is concluded the larger spherulite size of sample E compared to the samples A and B, which showed smaller spherulite structures and relatively homogenised morphology samples contributes to the early failure in the sample E, as the higher PP content increases the viscosity and void fraction in samples. Performance characteristics of samples $\mathrm{A}$ and $\mathrm{B}$ are superior to sample $\mathrm{E}$ attributable to higher $\mathrm{PE}$ content resulting in smaller spherulite size. It is also concluded that sample with 50:50 PP: PE performed the best (sample A), where the microcellular structure uniformly distributed.

\section{REFERENCES}

[1] Technical Plastic Extrusions. http://www.bellplastics.co.uk/wire_rope_coatings.html

[2] B. Cordage, "Technical Properties of Synthetic Fibres," 2012.

http://www.barry.ca/publtion/rt-technical-properties-of-sy nthetic-fibres-oct-08.pdf

[3] S. Doroudiani, C. B. Park and M. T. Kortschot, "Effect of the Crystallinity and Morphology on the Microcellular Foam Structure of Semicrystalline Polymers," Polymer Engineering and Science, Vol. 36, No. 21, 1996, pp. 2645-2662. doi:10.1002/pen.10664

[4] Y. V. Kissin, "Orientation of Isotactic Polypropylene in Crystalline and Amorphous Phases: IR Methods," Journal of Polymer Science: Polymer Physics, Vol. 21, No. 10, 1983, pp. 2085-2096. doi:10.1002/pol.1983.180211018 
[5] G. Lamberti, V. Brucato and G. Titomanlio, "Orientation and Crystallinity in Film Casting of Polypropylene," Journal of Applied Polymer Science, Vol. 84, No. 11, 2002, pp. 1981-1992.

[6] C. E. Miller, "Use of Near-Infrared Spectroscopy to Determine the Composition of High-Density/Low-Density Polyethylene Blend Films," Applied Spectroscopy, Vol. 47, No. 2, 1993, pp. 139-253. doi: $10.1366 / 0003702934048370$

[7] W. Camacho and S. Karlsson, "NIR, DSC, and FTIR as Quantitative Methods for Compositional Analysis of Blends of Polymers Obtained from Recycled Mixed Plastic Waste," Polymer Engineering and Science, Vol. 41, No. 9, 2001, pp. 1626-1635. doi:10.1002/pen.10860

[8] L. Bohn, "Incompatibility and Phase Formation in Solid Polymer Mixures and Graft and Block Copolymers," Rubber Chemistry and Technology, Vol. 41, No. 2, 1968, pp. 495-513. doi:10.5254/1.3547187

[9] J. W. Teh, A. Rudin and J. C. Keung, "A Review of Polyethylene-Polypropylene Blends and Their Compatibilization," Advances in Polymer Technology, Vol. 13, No. 1, 1994, pp. 1-23. doi:10.1002/adv.1994.060130101

[10] B. Z. Jiang, D. R. Uhlmann and J. B. Vander Sand, "Rubber-Toughening in Polypropylene," Journal of Applied Polymer Science, Vol. 30, No. 6, 1985, pp. 2485-2504. doi:10.1002/app.1985.070300617

[11] D. C. Yang, B. L. Zhang, Y. K. Yang, Z. Fang, G. Sun and Z. L. Feng, "Morphology and Properties of Blends of Polypropylene with Ethylene-Propylene Rubber," Polymer Engineering and Science, Vol. 24, No. 8, 1984, pp. 612-617. doi:10.1002/pen.760240814

[12] J. G. M. Van Gisbergen, W. F. L. M. Hoeben and H. E. H. Meijer, "Melt Rheology of Electron-Beam-Irradiated B1ends, of Polypropylene and Ethylene-Propylene-Diene Monomer (EPDM) Rubber," Polymer Engineering and Science, Vol. 31, No. 21, 1991, pp. 1539-1544.

[13] M. Jiang, "Physical Chemistry in Polymer Alloys," Sichuan Educational Press, Chengdu, 1988.

[14] L. Ubonnut, S. Thongyai and P. Praserthdam, "Block Copolymer of Polypropylene and Polyethylene by Way of Diisocyanate," Technology and Innovation for sustainable Development Conference, Khon Kaen, 25-26 January 2006.

[15] S. Devasahayam, "Interfacial Toughness in PolymerLayered Laminar Composites," Journal of Polymer Science Part B: Polymer Physics, Vol. 42, No. 20, 2004, pp.
3822-3835. doi:10.1002/polb.20250

[16] S. Devasahayam, "Towards Improving Wet-Adhesion in a Metal Oxide-Polymer Coating System," Journal of Applied Polymer Science, Vol. 99, No. 6, 2006, pp. 33183327. doi:10.1002/app.22759

[17] S. Devasahayam, "Effect of Moisture-Ingress on Adhesion Energy in a Metal Oxide-Polymer System," Journal of Applied Polymer Science, Vol. 99, No. 5, 2006, pp. 2052-2061. doi:10.1002/app.22588

[18] A. J. Lovinger and M. L. Williams, "Tensile Properties and Morphology of Blends of Polyethylene and Polypropylene," Journal of Applied Polymer Science, Vol. 25, No. 8, 1980, pp. 1703-1713. doi:10.1002/app.1980.070250817

[19] J. L. Way and J. R. Atkinson, “The Influence of Crystallization Temperature on the Deformation of Polypropylene Spherulites," Journal of Materials Science, Vol. 7, No. 1, 1972, pp. 1345-1346. doi:10.1007/BF00550703

[20] J. C. Halpin and J. L. Kardos, "Moduli of Crystalline Polymers Employing Composite Theory," Journal of Applied Physics, Vol. 43, No. 5, 1972, pp. 2235-2241. doi:10.1063/1.1661482

[21] P. J. Phillips and J. Patel, "The Influence of Morphology on the Tensile Properties of Polyethylenes," Polymer Engineering and Science, Vol. 18, No. 12, 1978, pp. 943950. doi:10.1002/pen.760181207

[22] F. J. Padden and H. D. Keith, "Crystallization in Thin Films of Isotactic Polypropylene," Journal of Applied Physics, Vol. 37, No. 11, 1966, pp. 4013-4020. doi:10.1063/1.1707968

[23] F. J. Padden and H. D. Keith, "Mechanism for Lamellar Branching in Isotactic Polypropylene," Journal of Applied Physics, Vol. 44, No. 3, 1973, pp. 1217-1223. doi:10.1063/1.1662331

[24] P. Rachtanapun, S. E. M. Selke and L. M. Matuana, "Effect of the High-Density Polyethylene Melt Index on the Microcellular Foaming of High-Density Polyethylene/ Polypropylene Blends," Journal of Applied Polymer Science, Vol. 93, No. 1, 2004, pp. 364-371. doi:10.1002/app.20428

[25] J. S. Petronyuk, O. V. Priadilova, V. M. Levin, O. A. Ledneva and A. A. Popov, "Structure and Elastic Properties of Immiscible LDPE-PP Blends: Dependence on Composition," Proceedings of Materials Research Society on Nanomaterials for Structural Applications, Vol. 740, Boston, 2-6 December 2002, pp. 261-266. 